Check for updates

Cite this: Mater. Adv., 2020 1,1866

Received 20th July 2020,

Accepted 26th July 2020

DOI: 10.1039/d0ma00528b

rsc.li/materials-advances

\title{
Ambient condition-processing strategy for improved air-stability and efficiency in mixed-cation perovskite solar cells $\dagger$
}

\author{
Ivy M. Asuo, (D) ab Dawit Gedamu, (D) ${ }^{\mathrm{b}}$ Nutifafa Y. Doumon, (D) ${ }^{\text {ac }}$ Ibrahima Ka, (D) ${ }^{a}$ \\ Alain Pignolet, ${ }^{a}$ Sylvain G. Cloutier*b and Riad Nechache (iD *a
}

\begin{abstract}
Fabrication of efficient halide perovskite solar cells under ambient conditions and their stability remain a challenge due to the sensitivity of halide perovskites to moisture, oxygen, light, and temperature. Thus, there is a strong demand and interest to develop a method for fabricating perovskite solar cells with long-term stability and even better, such a fabrication method under ambient conditions. To this end, we use a chemical synthesis method and a solvent engineering technique to optimize halide perovskite thin film deposition in an ambient environment. We obtained pinhole-free films composed of large crystal grains and high crystal quality that result in excellent optoelectronic properties of the halide perovskite. We also report a low trap-density in the order of $10^{15} \mathrm{~cm}^{-3}$ for the polycrystalline perovskite thin film. Moreover, with an $n-i-p$ solar cell structure, a maximum power conversion efficiency of $\sim 20.3 \%$ with excellent stability in ambient air $(25-55 \% \mathrm{RH})$ for more than ten months of storage (>7000 hours) is achieved. The optimized solar cell without encapsulation retained $\sim 80 \%$ of its initial performance after ten months of storage with a $T_{80}$ of $\sim 5035$ hours. Our findings suggest that the performance and stability of the perovskite solar cells are highly dependent on the device architecture, grain morphology, trap density, and carrier mobility in the device before and after storage.
\end{abstract}

\section{Introduction}

Halide perovskite photovoltaic cells have generated tremendous attention due to their promising material properties and lowtemperature processing from solution precursors. Halide perovskites have great potential as an alternative material for solar cells with a high power conversion efficiency (PCE) of up to $25.2 \%{ }^{1}$ Their effective photon absorption, ${ }^{2}$ low exciton binding energy, ${ }^{3}$ and tunable bandgap (1.5-2.2 eV $)^{4}$ are advantageous for applications such as light-emitting diodes (LEDs), ${ }^{5-7}$ photovoltaics $(\mathrm{PVs})^{8-10}$ and photodetector devices. ${ }^{11-13}$ Albeit the remarkable progress from the past few years, organic-inorganic halide perovskite (OIHP) processing and its stability under ambient conditions remain an open challenge towards commercialization. The shelf-lifetime of OIHP, especially $\mathrm{CH}_{3} \mathrm{NH}_{3} \mathrm{PbI}_{3}$-based devices

\footnotetext{
${ }^{a}$ INRS - Centre Énergie Matériaux Télécommunications, 1650 Boul. Lionel Boulet, Varennes (QC), J3X 1S2, Canada. E-mail: nechache@emt.inrs.ca

${ }^{b}$ École de Technologie Supérieure (ÉTS), Department of Electrical Engineering, 1100 rue Notre-Dame Ouest, Montréal (QC), H3C 1K3, Canada. E-mail: SylvainG.Cloutier@etsmtl.ca

${ }^{c}$ Photophysics and Optoelectronics, Zernike Institute for Advanced Materials, University of Groningen, Nijenborgh 4, NL-9747 AG, Groningen, The Netherlands $\dagger$ Electronic supplementary information (ESI) available. See DOI: 10.1039/ d0ma00528b
}

under ambient air conditions, is very short, ${ }^{14}$ and their performances decrease rapidly due to the extrinsic and intrinsic instabilities of the halide perovskites. ${ }^{15-17}$ For these reasons, OIHP material synthesis and thin film fabrication are usually conducted under an inert atmosphere. The use of glove box facilities is a substantial impediment for large scale OIHP-based device manufacturing. ${ }^{18}$ Thus, a halide perovskite material processable under ambient conditions, offering long-term stability and high performance, is currently in high demand. Recently, several methods have been explored to address this challenge through synthesis and structure optimization ${ }^{19,20}$ to achieve stable and compact halide perovskite thin films. The process of obtaining compact and large crystal grain thin film on a given substrate is challenging but crucial for high-performance devices. ${ }^{21}$ For optimum device performances, the ideal perovskite film should be pinhole-free, composed of large crystal grains, and have a smooth surface $^{22}$ with fewer grain boundaries. ${ }^{23,24}$ Therefore, recent investigations focus directly or indirectly on achieving high-quality perovskite films using a single, ${ }^{25}$ double, ${ }^{26}$ or triple cation ${ }^{27}$ system in order to increase both performance and stability of the devices. However, the ambient environment accelerates the degradation of OIHP of even high-quality perovskite films by promoting the rapid decomposition of OIHP material into optically-inert constituents such as $\mathrm{PbI}_{2} \cdot{ }^{14}$ Notwithstanding, a recent report proposed a 
triple-cation system with high efficiency and relatively good PV stability performance under continuous illumination ${ }^{27}$ and thermal stress. $^{28}$ Yet, all the material synthesis, device fabrication, and testing were performed under an inert atmosphere. ${ }^{27,28}$

Here, we describe a synthesis and processing technique entirely performed under ambient conditions. In addition, we characterize the devices only under ambient conditions for their efficiency and air-stability. We focus on tailoring perovskite grain size and crystal quality by using an ionic additive, lead thiocyanate $\left(\mathrm{Pb}(\mathrm{SCN})_{2}\right)$, and a solvent-antisolvent (ethanol and chlorobenzene) engineering technique for the mixed-cation perovskite. The use of ethanol and chlorobenzene for solvent treatment is known to promote the nucleation and growth of large grains and a good crystallization of the perovskite. ${ }^{29,30}$ Ethanol, in particular, contributes to the dissolution of the remnant MAI, FAI, and MABr, since these organic precursors of the perovskite are soluble in ethanol. Chlorobenzene, an antisolvent for the perovskite, is used for inducing the fast precipitation of the perovskite film, resulting in the growth of smooth, well-crystallized, and large grain perovskite films. The literature also advocates that when inserted into perovskite precursors, pseudohalide additives such as $\mathrm{Pb}(\mathrm{SCN})_{2}$ increase the tolerance of perovskite-based solar cells to relative humidities (RH\%) of above $70 \%{ }^{31,32}$ while conserving their microstructural properties. It also reduces radiative and non-radiative losses, thereby improving the device performance. ${ }^{33}$ The mixing of $\mathrm{Pb}(\mathrm{SCN})_{2}$ with $\mathrm{CH}_{3} \mathrm{NH}_{3} \mathrm{PbI}_{3}$ leads to the replacement of $\mathrm{I}^{-}$by $\mathrm{SCN}^{-}$in the precursor. Since $\mathrm{SCN}^{-}$works similarly as $\mathrm{I}^{-}$ (the halide), it is thus termed a pseudohalide.

The presence of thiocyanate $\left(\mathrm{SCN}^{-}\right)$anions in OIHP films does not upset the crystallographic structure of $\mathrm{CH}_{3} \mathrm{NH}_{3} \mathrm{PbI}_{3}$, since it has a similar ionic radius $(\sim 0.217 \mathrm{~nm})$ to iodine ions, $\mathrm{I}^{-}(\sim 0.220 \mathrm{~nm}) .{ }^{34} \mathrm{~Pb}(\mathrm{SCN})_{2}$ has been used as the precursor material or additive to synthesize pseudohalide perovskites for the improvement in microstructural and optical properties of $\mathrm{CH}_{3} \mathrm{NH}_{3} \mathrm{PbI}_{3}$. Over the years, $\mathrm{Pb}(\mathrm{SCN})_{2}$-doping of single ${ }^{35,36}$ or double cation ${ }^{26,37}$ perovskites has been studied towards largegrain and efficient perovskite devices. ${ }^{2,38}$ Most of the studies on pseudohalide perovskites (some processed under inert environments) indicated that the addition of pseudohalide could enhance the moisture-resistivity and quality of perovskite thin films. ${ }^{39}$ In our work, we adequately implemented $\mathrm{Pb}(\mathrm{SCN})_{2}$ in the triple cation perovskite in combination with a solventantisolvent precipitation technique under ambient conditions, therefore contributing not only towards improving the performance of our devices but also towards a much simple process, paving the way towards upscaling and applications. Using our optimized processing method, we produce compact perovskite films and large crystal grains with passivated grain boundaries. The perovskite thin-films are then used to fabricate $n-i-p-$ heterostructured solar cells. Very importantly, the whole fabrication and characterization process is carried out in ambient air $(25-55 \% \mathrm{RH})$. As a result, perovskite solar cells with high efficiency $(\sim 20.3 \%)$, and excellent long-term air-stability of more than ten months (and a $T_{80}$ of $\sim 5035$ hours) are achieved, a valuable point to be highlighted. In addition, trap-state densities and the charge transport mechanisms before and after device degradation have been evaluated through the space charge limited current (SCLC) method to understand the physical source of the degradation. The ability to develop our perovskite solar cells under ambient conditions coupled with their high-performance paves the way towards industrial production of low-cost, efficient, and long-term stable solar cells.

\section{Results and discussions}

A one-step solution process is used to synthesize the mixedhalide perovskite films. Details of the fabrication processes are presented in the Experimental section. The perovskite samples with and without the additive are labeled SOL- $x$ and SOL-0, respectively. The main difference between SOL-0 and SOL- $x$ (where $x$ is the weight percent of the additive) devices comes from the addition of thiocyanate anions (SCN), derived from $\mathrm{Pb}(\mathrm{SCN})_{2}$, to the precursor solutions before the deposition of the thin films. A range of weight percentages of the additive from $0-11 \mathrm{wt} \%$ was used to determine the optimum proportion of SCN to achieve the best performance of the solar cells, as shown in Fig. S1 (ESI $\dagger$ ). The optimum concentration of $5.8 \mathrm{wt} \%$ of the additive has been adopted for further investigations. That is, the devices with SOL-5.8 have been fabricated using a precursor solution containing approximately $5.8 \mathrm{wt} \%$ of the $\mathrm{Pb}(\mathrm{SCN})_{2}$ additive.

The top-view of the scanning electron microscopy (SEM) images of the SOL-0 and SOL-5.8 perovskite films are shown in Fig. 1(a) and (b), while Fig. S2 (ESI $\dagger$ ) shows the considered perovskite films without and with the complete concentration range of the ionic additive studied. In general, SOL- $x$ films seem to show better morphology. For instance, the SOL-0 film shows compact morphology and consists of fine grains with an average size of $\sim 200 \mathrm{~nm}$, while the SOL-5.8 film, remarkably, shows very dense, pinhole-free, and large grains $>2 \mu \mathrm{m}$ in size. Also, the micrograph of the SOL-5.8 film shows grain boundaries (GBs) with a brighter contrast between the grains upon the
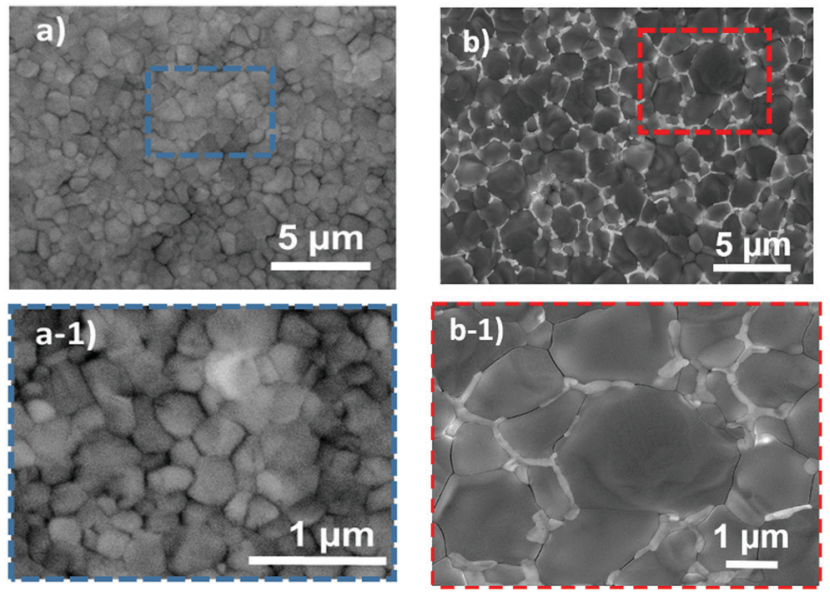

Fig. 1 SEM images of the perovskite films without the additive SOL-0 (a and a-1) and with $5.8 w t \%$ of the additive (SOL-5.8) (b and b-1). 
addition of $\mathrm{Pb}(\mathrm{SCN})_{2}$, as shown in Fig. 1(b) and (b-1). Such addition leads to an increased crystal size, reduced traps, and improved device stability of the perovskite films. The mechanisms for enlarged grains have been proposed to originate from lower Gibbs free energy for the nucleation due to the beneficial effect of the incorporated $\mathrm{SCN}^{-}$ion. ${ }^{37,40}$ Furthermore, during the perovskite film formation, there could be a reaction between $\mathrm{CH}_{3} \mathrm{NH}_{3^{+}}$ cations and $\mathrm{SCN}^{-}$anions, leading to the formation of $\mathrm{CH}_{3} \mathrm{NH}_{2}$ gas. ${ }^{39,41}$ The $\mathrm{CH}_{3} \mathrm{NH}_{2}$ gas is known to increase the grain size and the crystalline quality of the perovskite thin films. This could be the reason behind the grain enlargement of our thin films. Moreover, in a previous report, we demonstrated that solventantisolvent treatment of perovskite films also results in larger grains. ${ }^{30}$ These two phenomena led to fewer and passivated GBs, resulting in the reduced recombination and increased crystallite size. ${ }^{42,43}$

The X-ray diffraction (XRD) patterns acquired and shown in Fig. 2(a) and (b) exhibit strong and sharp peaks matching the tetragonal structure of the halide perovskites, in agreement with previous reports. ${ }^{27,30}$ These XRD spectra also demonstrate that, since there is no observable peak at $\sim 12.7^{\circ}$ in both spectra, the observed white regions at the grain boundaries are not predominantly $\mathrm{PbI}_{2}$, but are rather the $\mathrm{Pb}$-, I- and S-rich regions, as shown by the energy-dispersive X-ray spectroscopy (EDS) spectra and mapping images (Fig. S3, ESI $\dagger$ ) and by the Auger spectra (see Fig. S4(c)-(e), ESI $\dagger$ ). In general, the mechanism of formation of the white regions at the GBs instigates from a crystallization point of view. We observe that increasing the volume ratio of added ethanol (above 50\%) to chlorobenzene for the solvent treatment results in the enhancement of the $\mathrm{PbI}_{2}$ peak (figure not shown here), while keeping it below that threshold results in no strong $\mathrm{PbI}_{2}$ peaks. This explains why our optimum (SOL-5.8) films exhibited no $\mathrm{PbI}_{2}$ peaks on the XRD pattern. Fig. S3 (ESI $\dagger$ ) depicts the presence of all the major elemental components in the perovskite films. The elemental composition measurement of the perovskite films using EDS is challenging since the emission lines of $\mathrm{Pb}$ and $\mathrm{S}$ are very close and overlap in the spectrum ( $\mathrm{Pb}: \mathrm{M} \alpha 1=2.346 \mathrm{keV}$ and $\mathrm{S}$ : $\mathrm{K} \alpha 1=2.308 \mathrm{keV}$ ). Therefore, Auger electron spectroscopy (AES) was also used to determine the chemical composition of the films. As shown in Fig. S4c (ESI $\dagger$ ), the reference sample (SOL-0) displays the presence of peaks corresponding to $\mathrm{Pb}, \mathrm{I}$, and C. The spectrum for the dark region (1) of the SOL-5.8 sample is similar to that of the SOL-0 sample (Fig. S4d, ESI $\dagger$ ). We note that besides $\mathrm{Pb}$ and $\mathrm{I}$, sulfur is also present at the GBs (Fig. S4e, ESI $\dagger$ ) with higher $\mathrm{Pb}$ intensity. In brief, the
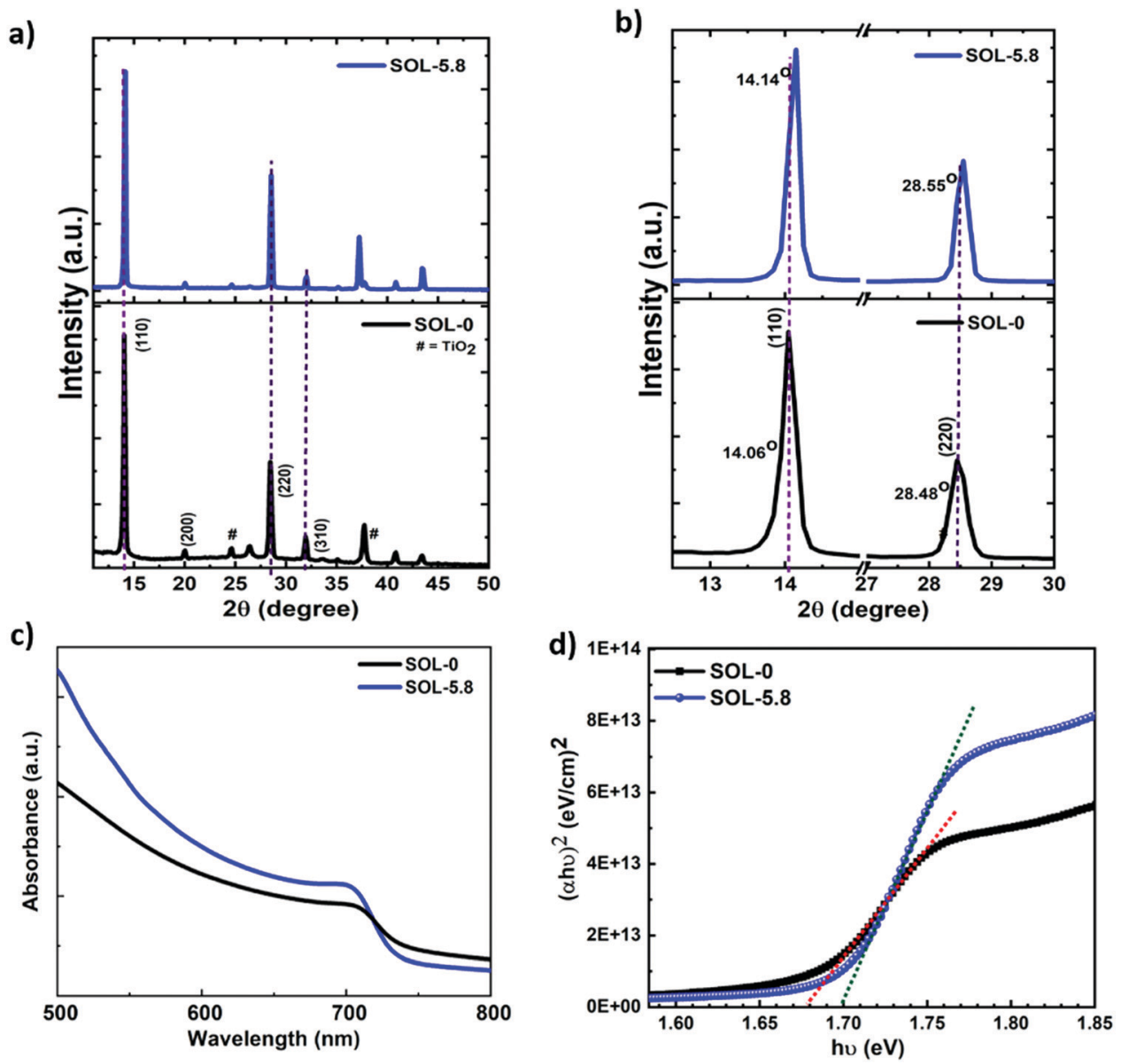

Fig. 2 XRD spectra of (a) the prepared perovskite films and (b) magnified plots of the (110) and (220) peaks in (a). (c) UV-vis absorption spectra and (d) Tauc plots obtained from the absorption spectra for the SOL-0 and SOL-5.8 samples. 
characterization reveals that the bright regions at the GBs are the $\mathrm{Pb}-, \mathrm{I}-$, and $\mathrm{SCN}^{-}$-rich phases. Generally, the presence of excess $\mathrm{Pb}^{2+}$ at the grain boundaries is beneficial and has an impact on charge-carrier injection, hysteresis, and the overall device performance of PSCs. ${ }^{44}$ Thus, we show that passivation of the GBs through the systematic introduction of $\mathrm{Pb}(\mathrm{SCN})_{2}$ and the solvent-antisolvent treatment can effectively increase the grain size, while avoiding the formation of excessive $\mathrm{PbI}_{2}$, and hence improve the performance of the solar cells.

Furthermore, the effect of the additive on the XRD peak positions is also revealed in Fig. 2(b). The SOL-5.8 films show better crystallinity compared to the SOL-0 films as shown by the peak intensities and their derived full width at half maximum (FWHM) values. The former shows more than a four-fold increase in intensity as compared to the latter (see Fig. S5a, ESI $\dagger$ ). The peaks associated with (110) and (220) planes of the perovskite, slightly shift to higher angles. For instance, there is a shift from $14.06^{\circ}$ to $14.14^{\circ}$ for the (110) plane as a consequence of the ionic additive, indicative of a smaller lattice parameter. ${ }^{37}$ The FWHM obtained from the (110) peak shows that the SOL-5.8 films possess better crystallinity with a value of $0.17^{\circ}$ with a crystallite size of $47.4 \mathrm{~nm}$ obtained from the Scherrer's equation. ${ }^{45}$ In contrast, the SOL-0 films exhibit a FWHM of $0.23^{\circ}$ with a crystallite size of $34.6 \mathrm{~nm}$. As such, the use of ionic additives and solvent treatment impacts the microstructural properties of the halide perovskites. We further characterized the optical properties of the perovskite films using UV-vis absorption spectroscopy. In Fig. 2(c), the absorption spectra suggest excellent light-harvesting properties with a broad and well-defined absorption band. The corresponding band gaps estimated from the Tauc plots are $1.68 \mathrm{eV}$ and $1.7 \mathrm{eV}$ for SOL-0 and SOL-5.8 perovskite films, respectively (Fig. 2(d)). In brief, we indeed improve the microstructural properties of the perovskite material, which are crucial parameters for an efficient thin-film-solar cell device.

To evaluate the photovoltaic performance of the perovskite materials with and without additives, we fabricate both planar $\mathrm{TiO}_{2}$ and mesoporous $\mathrm{TiO}_{2}$ solar cells. The planar solar cells have an incorporated $\mathrm{TiO}_{2}$ blocking layer, also known as compact layer $\mathrm{TiO}_{2}\left(\mathrm{CL}-\mathrm{TiO}_{2}\right)$, while the mesoporous solar cells have a Li-doped mesoporous $\mathrm{TiO}_{2}$ layer atop the $\mathrm{TiO}_{2}$ blocking layer (which we denote here as $\mathrm{MP}^{-\mathrm{TiO}_{2}}$ ). Fig. 3 presents the device architecture and the corresponding SEM cross-sectional image of the solar cells fabricated with the mesoporous $\mathrm{TiO}_{2}$ layer (See Fig. S5(b) and (c) for the planar configuration, ESI $\dagger$ ). The device structure is a full-stack multilayered structure of the 3D perovskite solar cell (PSC), showing each layer and junctions. Our conventional device geometry comprises of $\mathrm{FTO} / \mathrm{TiO}_{2} /$ perovskite/spiro-OMeTAD/Au with a $\sim 500 \mathrm{~nm}$ thickness of the perovskite film (Fig. 3(b)). The schematic in Fig. 3(c) presents the energy band alignment of the respective layers in the solar cells and the charge extraction paths upon solar irradiation. It is worth emphasizing here that the complete device fabrication has been performed under ambient laboratory conditions $\left(T=20-25{ }^{\circ} \mathrm{C}\right.$, $\mathrm{RH}=25-55 \% \mathrm{RH})$.

Fig. 4(a) shows the current density-voltage $(J-V)$ characteristics of the different solar cell configurations. SOL-0-CL represents the device fabricated with the CL-TiO ${ }_{2}$ as ETL, while SOL-5.8-CL and SOL-5.8-MP are the devices fabricated with the $\mathrm{CL}^{-} \mathrm{TiO}_{2}$ layer and the $\mathrm{CL}-\mathrm{TiO}_{2} / \mathrm{MP}^{-T i O} \mathrm{O}_{2}$ double layer, respectively, as ETL. The photovoltaic parameters of the solar cells fabricated under similar conditions, including the short circuit current density $\left(J_{\mathrm{sc}}\right)$, open-circuit voltage $\left(V_{\mathrm{oc}}\right)$, fill factor $(\mathrm{FF})$, and PCE are summarized in Table 1. The PCE results indicate that, in general, the SOL-5.8-CL devices outperformed the SOL-0-CL devices (18.1\% versus $10.97 \%$ for the best-performing cells). The sole use of the ionic additive resulted in an improvement of $\sim 64 \%$ in the PCE (also see Fig. S1, ESI $\dagger$ ). Furthermore, the solar cells with the $\mathrm{MP}^{-\mathrm{TiO}_{2}}$ layer exhibit a higher FF with a slight increase in the PCE to $20.3 \%$ with moderate hysteresis in the $J-V$ scan at $16 \mathrm{mV} \mathrm{s}^{-1}$ (Fig. 4(b)). From the cross-sectional SEM image in Fig. S5(c) (ESI $\dagger$ ), the perovskite film has quite a large thickness variation, which may be a possible reason for the low PCEs for PSCs with the CL-TiO planar structure. The hysteresis index (HI) for our optimized perovskite device, as estimated from the equation reported by Kim et $a .^{46}$ is 0.0022 . The corresponding PCE and $J_{\mathrm{sc}}$ outputs of the optimized device under continuous illumination are as shown in Fig. 4(c). The statistical distributions of $J_{\mathrm{sc}}, V_{\mathrm{oc}}, \mathrm{FF}$, and PCE for our different solar cells, illustrated in Fig. S6 (ESI $\dagger$ ), demonstrate good reproducibility.

The higher FF of the SOL-5.8-MP compared to that of the SOL-5.8-CL devices, resulting in higher PCE, is attributed to the a)

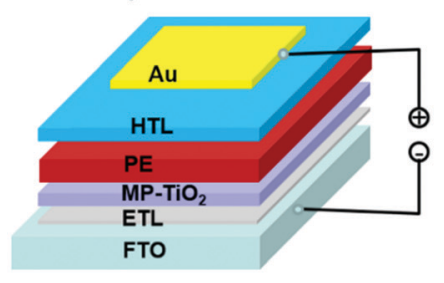

b)

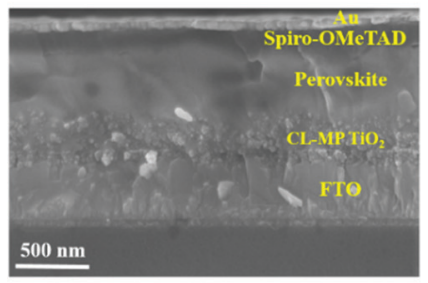

c)

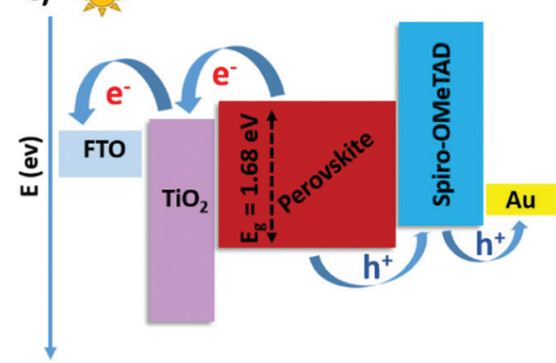

Fig. 3 (a) Device configuration for: glass/FTO/TiO $/$ perovskite/spiro-OMeTAD/gold. FTO is the bottom electrode. The first layer, which is a compact or mesoporous $\mathrm{TiO}_{2} \mathrm{n}$-type material, acts as an electron transport layer (ETL). A p-type third layer of spiro-OMeTAD acts as the hole-transport layer (HTL). Gold acts as the counter electrode. (b) A cross-sectional SEM image of a mesoporous $\mathrm{TiO}_{2}$-based solar cell corresponding to each layer in (a). (c) The schematic diagram of the energy band alignment shows the charge transport mechanism upon illumination. 


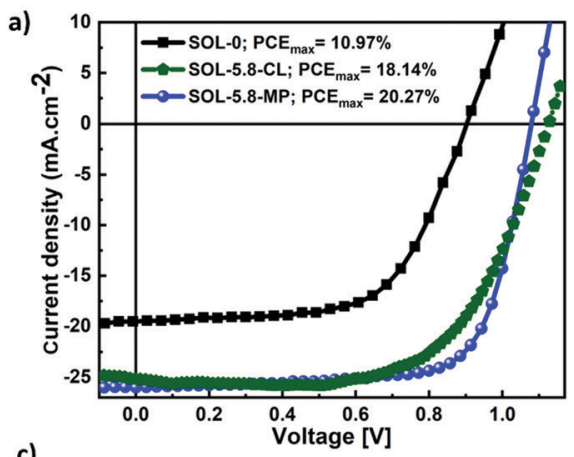

c)

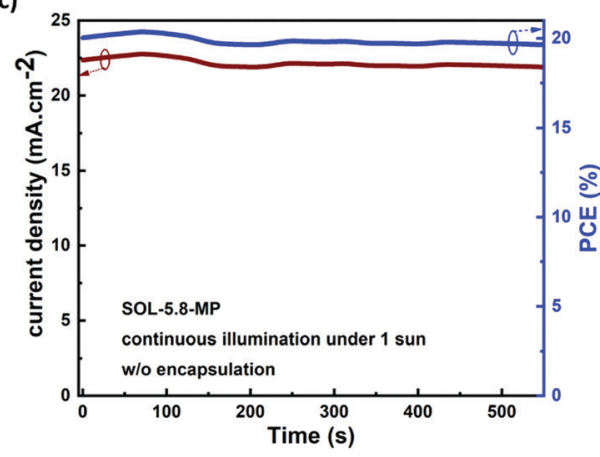

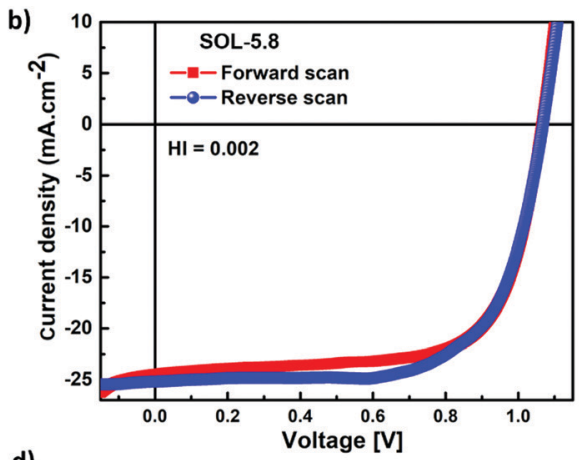

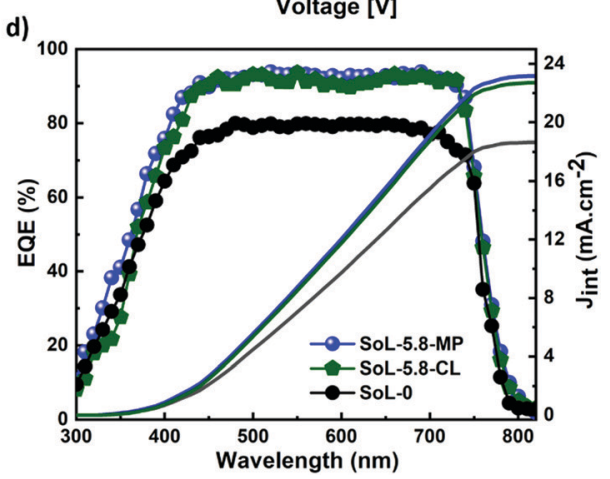

Fig. 4 (a) Typical J-V curves, obtained under AM1.5 illumination, of solar cell devices fabricated on compact TiO 2 (SOL-0-CL and SOL-5.8-CL) and mesoporous $\mathrm{TiO}_{2}$ (SOL-5.8-MP). The J-V characteristics were all measured in reverse scan directions. (b) $J-V$ scans in both forward and reverse directions at a rate of $16 \mathrm{mV} \mathrm{s}^{-1}$ for SOL-5.8-MP. (c) Steady-state current density and PCE output under maximum voltage (0.9 V) for the optimized device. (d) EQE spectra and the calculated integrated current density $\left(\mathrm{J}_{\mathrm{int}}\right)$ of the planar and mesoporous solar cells.

Table 1 Device parameters for solar cells made with the planar $\mathrm{TiO}_{2}$ layer and mesoporous $\mathrm{TiO}_{2}$ layer together with the average values and standard deviation

\begin{tabular}{|c|c|c|c|c|}
\hline \multirow[b]{2}{*}{ devices } & \multicolumn{4}{|l|}{$J-V$ Par. } \\
\hline & $J_{\mathrm{sc}}\left(\mathrm{mA} \mathrm{cm} \mathrm{cm}^{-2}\right)$ & $V_{\mathrm{oc}}(\mathrm{V})$ & $\mathrm{FF}(\%)$ & PCE (\%) \\
\hline SOL-0 ${ }^{a}$ & $19.50(19.09 \pm 0.56)$ & $0.91(0.90 \pm 0.01)$ & $61.9(58.24 \pm 4.85)$ & $11.0(9.73 \pm 0.65)$ \\
\hline SOL-5.8-CL ${ }^{b}$ & $24.98(24.43 \pm 0.35)$ & $1.13(1.08 \pm 0.03)$ & $64.3(61.56 \pm 2.54)$ & $18.1(16.43 \pm 1.12)$ \\
\hline SOL-5.8-MP ${ }^{c}$ & $25.79(25.04 \pm 0.43)$ & $1.08(1.06 \pm 0.03)$ & $72.8(71.46 \pm 1.23)$ & $20.31(9.05 \pm 0.95)$ \\
\hline
\end{tabular}

added Li-doped mesoporous- $\mathrm{TiO}_{2}$ layer, which facilitates efficient electron extraction at the perovskite- $\mathrm{TiO}_{2}$ interface and passivates trapping states in $\mathrm{TiO}_{2} \cdot{ }^{47,48}$ Moreover, the presence of the $\mathrm{MP}^{-\mathrm{TiO}_{2}}$ layer reduces the possible direct contact between the perovskite layer and the FTO electrode, which could occur due to the possible presence of tiny voids in the CL-TiO 2 layer (see Fig. S7(a)-(c) for the morphology of the $\mathrm{TiO}_{2}$ films). Hence, the mesoporous layer serves as a barrier to leakage current, limiting shunt pathways from the perovskite to the FTO. ${ }^{48}$ Fig. 4 (d) displays the external quantum efficiency (EQE) spectra of the solar cells that reach more than $90 \%$ in the range of $450-730 \mathrm{~nm}$. The integrated current densities $\left(J_{\text {int }}\right)$ as shown in Fig. 4(d) are $18.54 \mathrm{~mA} \mathrm{~cm}^{-2}, 22.73 \mathrm{~mA} \mathrm{~cm}^{-2}$ and $23.18 \mathrm{~mA} \mathrm{~cm}^{-2}$ for SOL-0-CL, SOL-5.8-CL, and SOL-5.8-MP, respectively. In general, the intensity of the EQE and $J_{\text {int }}$ improve upon the incorporation of the additives. This observation is in agreement with the increasing trend observed in the measured $J_{\mathrm{sc}}$ of the solar cells. We obtained slightly lower $J_{\text {int }}$ compared to measured $J_{\mathrm{sc}}$ values; however, these differences are within the acceptable measurement error margin. ${ }^{49,50}$ The EQE spectra demonstrate an efficient charge carrier extraction and a low carrier recombination rate for all our different devices due to the reduced density of grain boundary regions that act as carrier-trapping sites. ${ }^{51}$ Therefore, reducing the density and passivating the grain boundaries boosts charge carrier extraction with minimum losses at recombination sites within the perovskite films. ${ }^{52}$ Generally, voids at the grain boundaries are known to be detrimental to the stability of perovskite-based solar cells as they constitute an accessible channel for moisture (water molecules) to penetrate the perovskite film. ${ }^{53}$ As we establish later by using the space-chargelimited current (SCLC) method, the trap-state density for charge carriers at the perovskite interfaces, the ion migration within the perovskite film, and an unbalanced charge carrier mobility or transport all lead to a hysteresis effect. ${ }^{54}$ However, possibly because of the presence of a grain boundary phase, 
a)

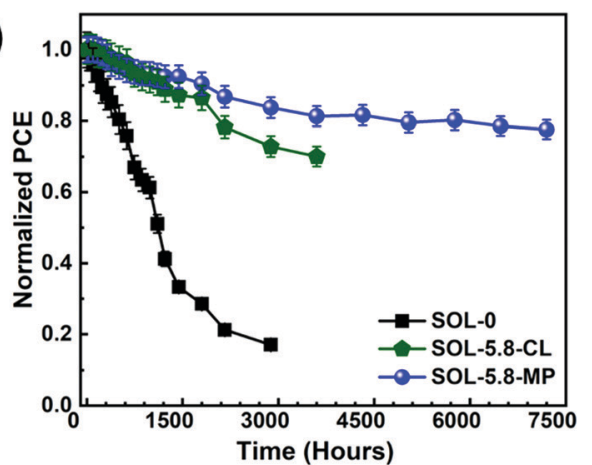

c)

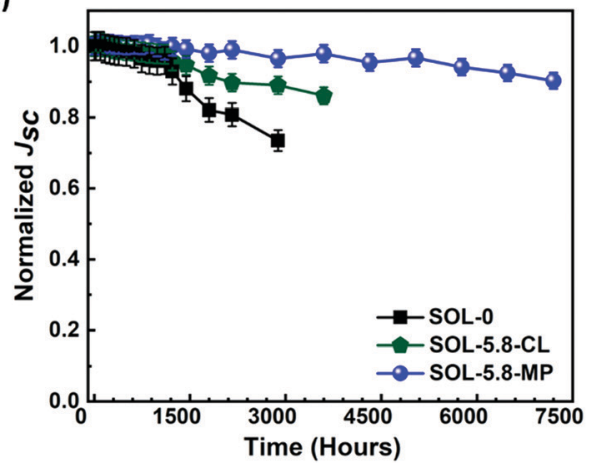

b)

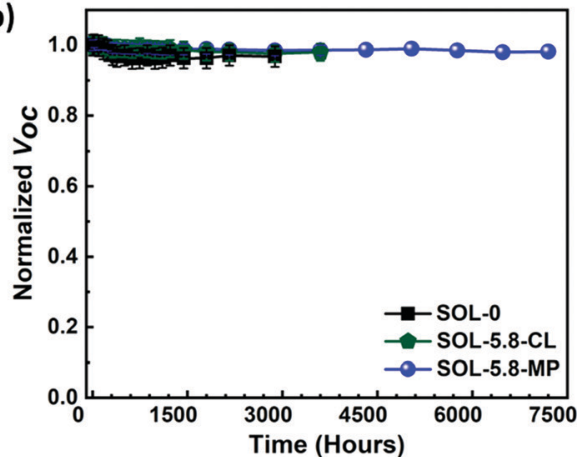

d)

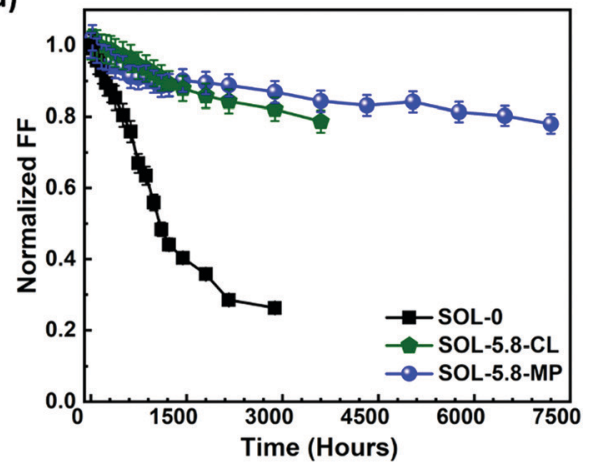

Fig. 5 Evolution of $J-V$ parameters (a) PCE, (b) $V_{\mathrm{oc}}$, (c) $J_{\mathrm{sc}}$, and (d) FF for the different devices measured at different periods over ten months. Devices are always stored and measured under ambient laboratory conditions $\left(T=22-25{ }^{\circ} \mathrm{C}\right.$, and $\left.\mathrm{RH}=25-55 \% \mathrm{RH}\right)$.

such hysteresis is not observed for our high photovoltaic performance $\mathrm{MP}^{-\mathrm{TiO}_{2}}$ based solar cell devices, which also show little degradation.

We further investigate the long-term stability of several batches of devices prepared in identical conditions without any encapsulation. The bare devices are always kept in the ambient laboratory environment. The photovoltaic parameters under AM 1.5G are measured at different times over ten months and are shown in Fig. 5.

As presented in Fig. 5(a), the SOL-0 solar cells degrade the fastest, with more than $50 \%$ of the PCE loss after the first 1200 hours. In contrast, SOL-5.8-based devices show remarkable stability with a $10 \%$ loss and only $6.6 \%$ loss in PCE for SOL-5.8-CL and SOL-5.8-MP, respectively. The most significant finding is that the SOL-5.8 solar cells are substantially more stable than the SOL-0-based solar cells as anticipated from the passivated grain boundaries. Indeed, the addition of $\mathrm{SCN}^{-}$improves the efficiency and stability of these perovskites by strong $\mathrm{S}-\mathrm{C}-\mathrm{N}$ intermolecular bonds in the perovskite lattice structure. ${ }^{31,32}$

We also obtained a long lifetime for the SOL-5.8-MP solar cells as determined by the $T_{80}$ parameter (the time at which the device loses $20 \%$ of its initial PCE). ${ }^{55}$ Our solar cells exhibit a $T_{80}$ of 523 hours for SOL-0-CL, 2091 hours for SOL-5.8-CL, and 5035 hours for SOL-5.8-MP, respectively. Notably, our recorded lifetime of $>5000$ hours is among the best-reported $T_{80}$ so far for ambient condition-stable perovskite solar cells. ${ }^{5,56}$ Fig. 5(b)-(d) display the degradation of the other $J-V$ parameters. There, the devices show relatively constant $V_{\text {oc }}$ with minimal variation in all three devices. The $J_{\mathrm{sc}}$ and especially FF show substantial degradation.
The FF degradation remains the dominant contributor to the PCE degradation in all the devices.

Seeking to unveil the device performance intricacies in terms of efficiency and stability, the trap-state densities and the charge transport ${ }^{57-59}$ mechanisms have been evaluated in both fresh and degraded single-carrier devices by the SCLC method. ${ }^{58,60}$ The hole-only (H-O) devices suppress the injection of electrons at the electrodes, while the electron-only (E-O) devices limit the injection of holes. Fig. 6(a)-(c) compare the log-scale $J-V$ characteristics of the single-carrier devices, from which the trap density can be derived using the equation: ${ }^{61}$

$$
N_{\mathrm{t}}=\frac{2 \varepsilon \varepsilon_{0} V_{\mathrm{TFL}}}{q L^{2}} .
$$

The voltage at which the trap states are filled with charge carriers is known as the trap-filled limit voltage $\left(V_{\text {TFL }}\right) . N_{\mathrm{t}}$ is the trap density, $q$ is the electronic charge, $L$ is the thickness, $\varepsilon$ is the dielectric constant of the material, and $\varepsilon_{0}$ is the vacuum permittivity.

Fig. 6(a)-(c) display the log-scale $J-V$ curves measured for the fresh and partially-degraded (after 240 hours or 10 days storage under ambient conditions) single-carrier devices with the corresponding $V_{\text {TFL }}$. From the $V_{\text {TFL }}$, the trap densities can be obtained using eqn (2) ${ }^{61}$ and are displayed in Table 2 . In the fresh state, we observe a low trap-state density (down to $10^{15}$ ) in our perovskite thin films, which slightly increase after exposure to humidity $(35 \% \pm 5 \mathrm{RH})$. This increment in $N_{t}$ might contribute to the observed overall degradation over time. ${ }^{57}$ However, the real reason behind the observed degradation trends 

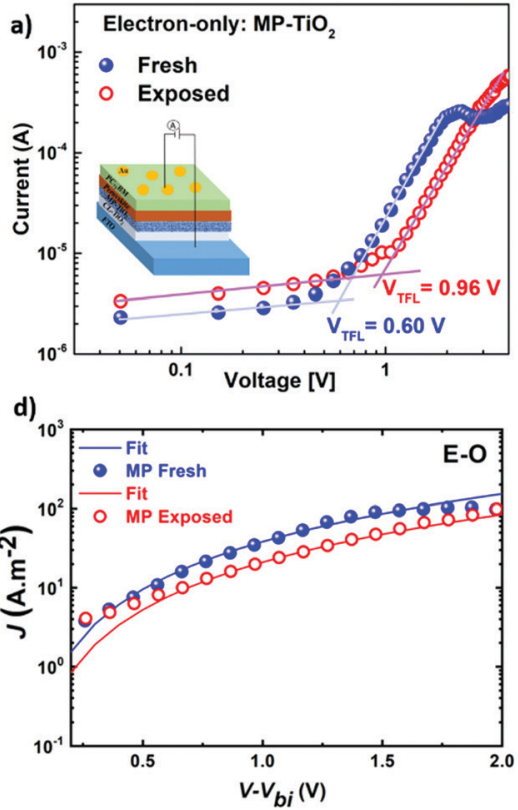
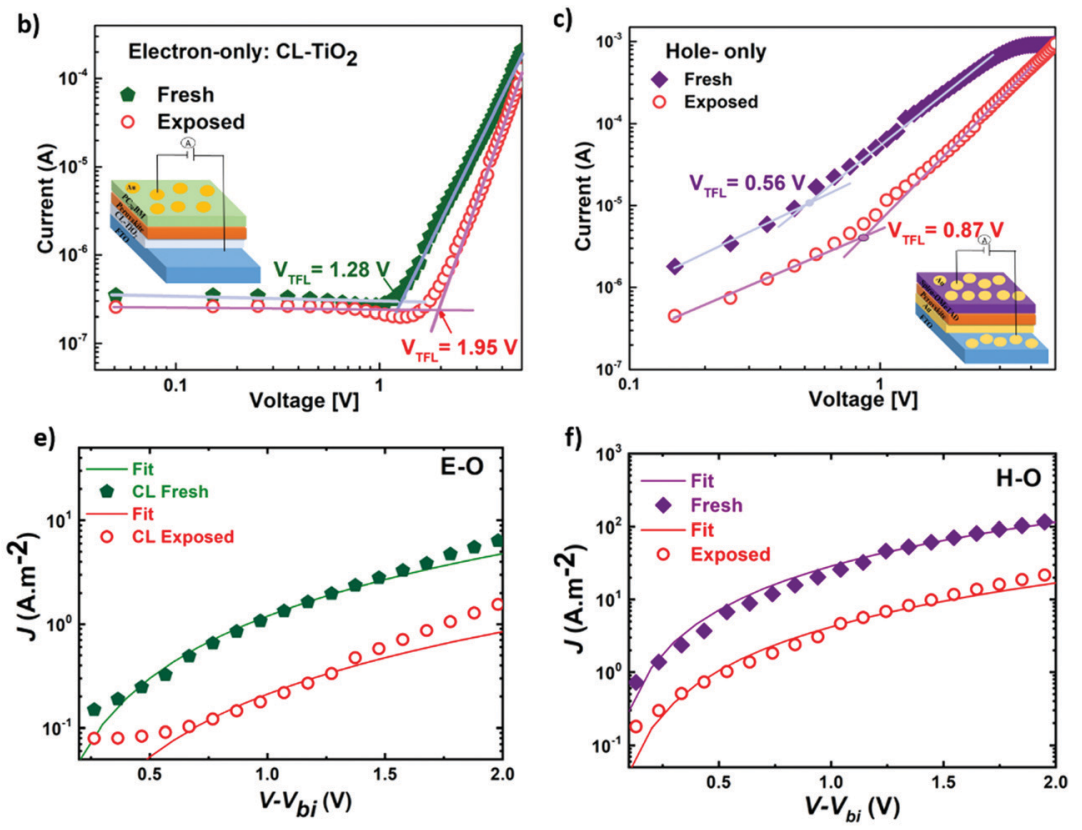

Fig. 6 (a-c) Log-scale $J-V$ curves in the dark indicating the trap-filled voltages $\left(V_{\text {TFL }}\right)$ and showing fitted curves (d-f) with the Mott-Gurney equation ${ }^{62}$ (SCLC method) for mobilities for fresh and exposed (240 hours under ambient conditions) electron-only devices (a and d) FTO/CL-MP-TiO $/ 2 / S O L-5.8$ / $\mathrm{PC}_{71} \mathrm{BM} / \mathrm{Au}$ device and (b and e) $\mathrm{FTO} / \mathrm{CL}-\mathrm{TiO}_{2} / \mathrm{SOL}-5.8 / \mathrm{PC}_{71} \mathrm{BM} / \mathrm{Au}$ device; hole-only device (c and f) FTO/Au/SOL-5.8/spiro-OMeTAD/Au device. Insets: Electron-only device structures of (a) $\mathrm{MP}^{-\mathrm{TiO}_{2}}$, (b) $\mathrm{CL}-\mathrm{TiO}_{2}$ and (c) hole-only device structure.

$\left(\mathrm{MP}-\mathrm{TiO}_{2} \gg \mathrm{CL}-\mathrm{TiO}_{2} \gg \mathrm{SOL}-0\right)$ remains unclear as the trap density increase does not readily correlate with the observed degradation and lifetime.

Any change in the charge transport (before and after exposure) may help explain the observed degradation trend. When the ratio of mobilities of electrons and holes is close to unity, there is a balanced charge transport. Imbalance in charge mobilities of electrons and holes before and after degradation has been suggested to be associated with the different carrier extraction rates and a reason behind the drop in $\mathrm{FF}^{65-67}$ Therefore, to elucidate this issue further, we determined the charge carrier mobilities ${ }^{63,64}$ and the ratio of mobilities using the SCLC method as previously described. ${ }^{66}$ Though the SCLC method is simplistic, it has been used to determine carrier mobilities in the thin-film perovskite devices. ${ }^{63,64}$ The $J-V$ curves of the fresh and exposed devices in Fig. 6(d)-(f) have been fitted to the Mott-Gurney equation ${ }^{62}$ to determine the charge carrier mobilities in the perovskite films.

$$
J_{\mathrm{SCLC}}=\frac{9}{8} \varepsilon_{0} \varepsilon_{\mathrm{r}} \mu \frac{V^{2}}{L^{3}} .
$$

where $J$ is the SCLC density, $\varepsilon_{0}$ and $\varepsilon_{\mathrm{r}}$ are the electric permittivities of free space and the relative dielectric constant of the active layer, respectively, $\mu$ is the charge carrier mobility, $V$ is the applied voltage, and $L$ is the thickness of the device.

Table 2 suggests a high degree of imbalance in electron and hole mobilities in fresh $\mathrm{CL}-\mathrm{TiO}_{2}$ cells (with a ratio of 24) compared to fresh $\mathrm{MP}^{-\mathrm{TiO}_{2}}$ cells (with a ratio of 1.3). The good balance in charge mobility of $\mathrm{MP}^{-\mathrm{TiO}_{2}}$ cells also explains the high $\mathrm{FF}$ of the $\mathrm{MP}^{-\mathrm{TiO}_{2}}$ cells, as seen in Table 1. It has been reported that unbalanced mobilities induce the build-up of space charge within the devices, reducing the charge extraction, and increasing the charge carrier densities. ${ }^{66}$ Bearing this in mind, even though there is an increase in this ratio for the degraded $\mathrm{MP}^{-\mathrm{TiO}_{2}}$ devices from 1.3 to 5 , this is still a much smaller charge carrier imbalance than that of the fresh or degraded $\mathrm{CL}-\mathrm{TiO}_{2}$ devices, which remains as high as 20 . Hence, we conclude that imbalance in charge transport is a possible reason for the observed reduction in the FF, which is the strongest contribution to the PCE degradation, in turn, explaining the fact that the SOL-5.8-MP solar cells are significantly more stable than the SOL-5.8-CL cells.

Table 2 Trap-state densities and mobilities of single-carrier devices with a compact (CL) $\mathrm{TiO}_{2}$ layer and mesoporous (MP) $\mathrm{TiO}_{2}$ layer. E-O: electron-only and $\mathrm{H}-\mathrm{O}$ : hole-only

\begin{tabular}{llllr}
\hline Devices & $\begin{array}{l}\text { Trap density fresh } \\
\left(\times 10^{16} \mathrm{~cm}^{-3}\right)\end{array}$ & $\begin{array}{l}\text { Trap density exposed } \\
\left(\times 10^{16} \mathrm{~cm}^{-3}\right)\end{array}$ & $\begin{array}{l}\text { Mobility }(\mu) \text { fresh } \\
\left(\times 10^{-6} \mathrm{~cm}^{2} \mathrm{~V}^{-1} \mathrm{~s}^{-1}\right)\end{array}$ & $\begin{array}{r}\text { Mobility }(\mu) \text { exposed } \\
\left(\times 10^{-6} \mathrm{~cm}^{2} \mathrm{~V}^{-1} \mathrm{~s}^{-1}\right)\end{array}$ \\
\hline E-O (with CL-Ti $\left.\mathrm{O}_{2}\right)$ & 1.50 & 2.29 & 6.25 & 1.10 \\
E-O (with MP-Ti O O & 1.13 & 200 & 110 \\
H-O & 0.70 & 1.02 & 150 & 22
\end{tabular}

The obtained mobility values of the fresh devices are comparable to those reported in the literature. ${ }^{63,64}$ 
Moreover, it is known that the FF is linked to the ratio of the extraction and recombination rates, and the mobilities of electrons and holes do affect both of them. ${ }^{68}$ Thus, the continuous drop in the FF (Fig. 5(d)) during the stability test narrows the origin of the degradation process down to a variation in recombination and/or extraction rates (evidenced by the drop in electron and hole currents seen in Fig. 6(d)-(f), but also by an increase in trap-state densities), to an imbalance in charge carrier mobilities. ${ }^{66}$ Therefore, the very low electron current measured for the $\mathrm{CL}^{-} \mathrm{TiO}_{2}$ devices (Fig. 6(e)) compared to that of the $\mathrm{MP}^{-\mathrm{TiO}_{2}}$ devices (Fig. 6(d)) could partly explain the observed degradation trend. Additionally, it is important to note that the better performance of the $\mathrm{MP}^{-\mathrm{TiO}_{2}}$ cells in terms of PCE is consistent with the lower trap-state density and charge balance compared to that of the $\mathrm{CL}^{-} \mathrm{TiO}_{2}$ devices. The detailed mechanisms behind the drop in mobilities (and the imbalance in charge transport) upon degradation are still unclear and beyond the scope of this work. Plans for further studies into the individual factors that may affect the performance of our solar cells are currently underway and would be based on the International Summit on Organic Photovoltaic Stability (ISOS) procedures. We believe that the ionic additive and solvent-anti solvent treatment play a crucial passivation role, resulting in the formation of pinhole-free and large grains, which helps to reduce the degradation rate of the perovskite material by preventing moisture penetration and accumulation. $\mathrm{SCN}^{-}$doping produces the stable pseudohalide perovskite due to enhanced chemical bonding in the lattice due to both strong ionic interactions between $\mathrm{S}-\mathrm{C}-\mathrm{N}$ and adjacent $\mathrm{Pb}$ and extra hydrogen bonding between $\mathrm{SCN}^{-}$and $\mathrm{CH}_{3} \mathrm{NH}_{3}{ }^{+} \cdot{ }^{32}$ Additionally, the free energy difference $\Delta H$ for the decay being positive for the former and harmful for the latter, the SCN-doped perovskite does not spontaneously decay, unlike $\mathrm{CH}_{3} \mathrm{NH}_{3} \mathrm{PbI}_{3}{ }^{32}$

\section{Conclusion}

In summary, a new reproducible method for ambient-condition fabrication of highly crystalline, compact, and large-grain halide perovskite films is presented. This new method is used for highly efficient and stable photovoltaic device integration. We have compared the perovskite solar cells undoped and doped with SCN using the perovskite precursors without (SOL-0) and with an optimal concentration of $\mathrm{Pb}(\mathrm{SCN})_{2}$ (SOL-5.8) atop both dense $\mathrm{TiO}_{2}\left(\mathrm{CL}-\mathrm{TiO}{ }_{2}\right)$ and mesoporous $\mathrm{TiO}_{2}$ on $\mathrm{TiO}_{2}$ $\left(\mathrm{MP}^{-\mathrm{TiO}_{2}}\right)$ films as electron transport layers. The best performing device reaches a maximum power conversion efficiency of $20.3 \%$ under standard AM1.5G illumination with excellent reproducibility. Remarkably, the SOL-5.8-MP devices without any encapsulation show less than 20\% PCE degradation after over 7000 hours ( $\sim 10$ months) of exposure to ambient room conditions. The remarkable performance of these solar cells is mainly due to their superior structural quality with compact morphology, large grain size, reduced grain boundaries, and low-trap density, as well as to the better inherent stability of the pseudohalide perovskite. We also related the trap density and charge mobility in the perovskite devices to the reduced current density and fill factors of the devices stored under ambient room conditions. Our research work provides an important pathway towards the fabrication of ambient condition-processed, high efficiency, and stable perovskite solar cells using this precursor-based method.

\section{Experimental methods}

The solvents and precursors were purchased from Ossila and Sigma Aldrich, unless otherwise stated, and used as received without any further modifications.

\section{Preparation of electron transport layers and perovskite films}

Fluorine-doped tin oxide (FTO) (TEC 15, 12-14 $\Omega \mathrm{sq}^{-1}$ ) glass substrates were used for the devices. The substrates were cleaned by ultrasonication with Hellmanex soap (10\%) in water, deionized water, acetone, and isopropanol successively for 10 minutes and then dried with compressed air. The cleaned substrates were then treated with UV-ozone for 20 minutes preceding titanium dioxide $\left(\mathrm{TiO}_{2}\right)$ deposition. Planar and mesoscopic solar cells with the following configuration FTO/CL-TiO ${ }_{2} /$ perovskite/spiro-OMeTAD/Au and FTO/CL-TiO $2 / \mathrm{MP}^{-\mathrm{TiO}_{2}} /$ perovs- $^{-}$ kite/spiro-OMeTAD/Au were fabricated. Each material was sequentially deposited via layer-by-layer spin-coating. First, a $\sim 50 \mathrm{~nm}$ compact $\mathrm{TiO}_{2}$ layer (Ti-nanoxide BL/SC, Solaronix SA) was spincoated onto the cleaned FTO substrates, then annealed at $550{ }^{\circ} \mathrm{C}$ for 45 minutes in a quartz tube furnace and finally cooled down to room temperature. In the case of the second configuration, diluted (in ethanol 6:1 volume ratio) mesoporous $\mathrm{TiO}_{2}$ (Great cell 30 NR-D) was spin-coated atop the compact $\mathrm{TiO}_{2}$ layer. The substrates were annealed at $500{ }^{\circ} \mathrm{C}$ for $30 \mathrm{~min}$ in air. After cooling the substrates to room temperature, lithium-doping of the mesoporous layer was carried out, following a modified method already described elsewhere. ${ }^{27}$ The mixed-cation-mixed halide perovskite of the form $\mathrm{Cs}_{x}\left(\mathrm{MA}_{0.17} \mathrm{FA}_{0.83}\right) \mathrm{Pb}_{(100-x)}\left(\mathrm{I}_{0.83} \mathrm{Br}_{0.17}\right)_{3}$ was modified by doping with lead thiocyanate to be resilient under ambient conditions and then used to prepare our solution (SOL-0). 2.9, 5.8, 9.4, and $11.1 \mathrm{wt} \%$ of SCN ions were added to the reference perovskite solution. To obtain the mixed-cation-mixed halide perovskite solution, we dissolved 0.6 M methylammonium iodide, $0.2 \mathrm{M}$ methylammonium bromide, $1 \mathrm{M}$ formamidinium iodide, $0.8 \mathrm{M}$ lead(II) iodide and 0.5 M lead(II) bromide in mixed solvent DMSO/DMF at a $1: 4$ volume ratio. Then, a proportion of $1.5 \mathrm{M}$ cesium iodide solution in DMSO was added to the perovskite solution and stirred gradually for one hour. No pre-heating of the solution was required before their deposition. The perovskite solution ${ }^{69}$ was then deposited onto the glass/FTO/TiO 2 layer and spin-coated at $2000 \mathrm{rpm}$ for $20 \mathrm{~s}$ to obtain the desired thickness. In a dynamic spin-coating mode, the solvent-antisolvent treatment (chlorobenzene: ethanol in voume ratios) was carried out and spun at $5000 \mathrm{rpm}$ for $10 \mathrm{~s}$. After spin coating, the films were then annealed at $125{ }^{\circ} \mathrm{C}$ for 15 minutes to complete the crystallization process of the perovskite and to evaporate the excess solvents. The fabrication steps took place under ambient conditions: $22-25{ }^{\circ} \mathrm{C}$, and $25-55 \% \mathrm{RH}$. 


\section{Device fabrication}

The perovskite solutions were deposited on the substrates and processed by using the two-step spin coating method described above. The first step was the casting of the perovskite precursor solution onto the $\mathrm{FTO} / \mathrm{TiO}_{2}$ layer, followed by solvent-antisolvent (a mixture of ethanol and chlorobenzene) dripping. The films were then annealed to complete the crystallization process of the perovskite and to evaporate the excess solvents. The hole-transporting material, spiro-OMeTAD, was subsequently

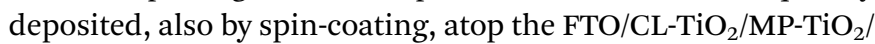
perovskite layer. The spiro-OMeTAD solution was prepared following a previously reported procedure. ${ }^{21}$ The spiroOMeTAD solution was then spin-coated atop the perovskite at $3500 \mathrm{rpm}$ for 30 seconds in ambient air. The devices were stored under ambient conditions for 24 hours prior to the contact deposition. Finally, the devices were completed by thermal evaporation of a $100 \mathrm{~nm}$ gold layer to serve as a top electrode, deposited at $0.2 \mathrm{~nm} \mathrm{~s}^{-1}$ at a pressure of $5 \times 10^{-5}$ Torr. The active illuminated area for all the devices was $0.45 \mathrm{~cm} \times$ $0.15 \mathrm{~cm}$, as defined by the area of the mask.

\section{Single-carrier device fabrication}

The single-carrier devices also were fabricated by the spincoating method. The hole-only devices were fabricated by depositing a $\sim 60 \mathrm{~nm}$ gold layer on top of FTO via thermal evaporation, followed by spin-coating the perovskite precursor solution at $2000 \mathrm{rpm}$ for $25 \mathrm{~s}$; then the spiro-OMeTAD solution was spin-coated at $3000 \mathrm{rpm}$ for $30 \mathrm{~s}$ and finally $\sim 80 \mathrm{~nm}$ of the gold layer as the top electrode was deposited via thermal evaporation. The electron-only devices were fabricated by spin-coating the perovskite solution on the $\mathrm{FTO} / \mathrm{TiO}_{2}$ layer at $2000 \mathrm{rpm}$ for $25 \mathrm{~s}$, followed by spin-casting [6,6]-phenyl- $\mathrm{C}_{71^{-}}$ butyric acid methyl ester $\left(\mathrm{PC}_{71} \mathrm{BM}\right)$ solution $\left(15 \mathrm{mg} \mathrm{ml}^{-1}\right.$ in chlorobenzene) at $1500 \mathrm{rpm}$ for $30 \mathrm{~s}$, and finally, the gold electrode was thermally evaporated. Note that, after each step of depositing the perovskite layers, they were annealed, and cooled down to room temperature before spin-coating the following top layers. The active transport layer of the devices used for the stability measurement was also exposed to ambient conditions before the evaporation of the top electrodes.

\section{Materials and device characterization}

The morphologies of the films were characterized by SEM, using a Hitachi SU 8230 ultra-high-resolution field emission scanning electron microscope. X-ray powder diffraction (XRD) patterns of the polycrystalline material were collected using a Bruker-AXS D8 Advance X-ray diffractometer with $\mathrm{Cu} \mathrm{K} \alpha 1$ radiation ( $\lambda=1.5406 \AA$ ). JEOL JAMP-30 was used for the Auger electron spectroscopy (AES) measurement. It was equipped with $\mathrm{a} \mathrm{LaB}_{6}$ electron gun and was operated at $10 \mathrm{kV}$ during the analysis. The Auger detector is a cylindrical mirror analyzer (CMA) and can detect Auger electrons from 0 to $3 \mathrm{keV}$. The acquisition system software was upgraded from the original to the one made by Geller MicroAnalytical Laboratory, Inc. (GMAL). The spectral measurements were done by placing the beam on the area of interest and collecting a 0-1000 eV spectrum, which takes about 1 minute. The electron beam current used was $5 \times 10^{-7}$ Amp.

The absorption spectra of the films were obtained using a UV/VIS/NIR spectrophotometer (PerkinElmer Lambda 750). The $J-V$ characteristics were measured with a Keithley 2400 source meter under AM1.5G illumination at $100 \mathrm{~mW} \mathrm{~cm}^{-2}$ using a Newport solar simulator (Newport, model 91160-1000). Finally, external quantum efficiency (EQE) measurements and integrated current density calculations were performed following the same procedure as the one reported previously. ${ }^{70}$ The photocurrent spectrum was measured using a xenon lamp coupled to a TRIAX320 monochromator equipped with a chopper and a lock-in amplifier (Ametek 1256) at zero bias. The light from the xenon lamp passes through the monochromator and was then modulated at $100 \mathrm{~Hz}$ before arriving on the solar cell placed behind a circular diaphragm of diameter $0.18 \mathrm{~cm}$. The photocurrent, $I(\lambda)$, was measured utilizing the lock-in amplifier. The EQE was calculated using the formula: $100 h c I(\lambda) / q \lambda P(\lambda)$, where $c$ is the speed of light, $h$ is the Planck constant, and $q$ is the electronic charge. The incident power, $P(\lambda)$, was measured with a calibrated photodiode (Newport 918D) placed at the position of the sample with the same diaphragm aperture. The integrated current density $\left(J_{\text {int }}\right)$ is calculated from the EQE data, using the equation: $J_{\text {int }}=q \int_{300 \mathrm{~nm}}^{780 \mathrm{~nm}} F(\lambda) \operatorname{EQE}(\lambda) \mathrm{d} \lambda$, where $F(\lambda)$ is the photon flux as a function of the wavelength in units of $\mathrm{W} \mathrm{cm}{ }^{-2} \mathrm{~nm}^{-1}$ under AM1.5G illumination and $q$ is the electron charge. We used the photon flux values downloaded from the internet (http://rredc.nrel.gov/solar/spectra/am1.5/).

The power of the incident light was measured using a calibrated photodiode (Newport 918D). The hysteresis index (HI) was determined by using the modified relation: ${ }^{46}$

$$
\text { Hysteresis index }=\frac{J_{\mathrm{rev}}\left(0.8 V_{\mathrm{oc}}\right)-J_{\mathrm{fwd}}\left(0.8 V_{\mathrm{oc}}\right)}{J_{\mathrm{rev}}\left(0.8 V_{\mathrm{oc}}\right)} .
$$

where $J_{\text {rev }}\left(0.8 V_{\text {oc }}\right)$ represents the current density at $80 \%$ of $V_{\text {oc }}$ for the reverse scan and $J_{\text {fwd }}\left(0.8 V_{\text {oc }}\right)$ is the current density at $80 \%$ of $V_{\text {oc }}$ for the forward scan, respectively.

\section{Conflicts of interest}

The authors declare no competing financial and/or nonfinancial interests in relation to this work. The authors also declare no conflict of interest.

\section{Acknowledgements}

I. M. A. acknowledges the UNESCO Chairs of MATECSS for her PhD Excellence Scholarship. I. M. A. and I. K. are thankful to the FRQNT for their doctoral and postdoctoral fellowships, respectively. S. G. C., R. N., and A. P. are thankful to the NSERC Discovery Program. S. G. C. also thanks the Canada Research Chairs and the FRQNT-Team program for their financial support. N. Y. D. acknowledges the financial support from the 
Zernike Bonus Incentive Scheme. The authors would also like to acknowledge S. Basu for her help with some measurements.

\section{References}

1 https:/www.nrel.gov/pv/assets/images/efficiency-chart-2018 0716.jpg.

2 I. M. Asuo, D. Gedamu, I. Ka, L. F. Gerlein, F.-X. Fortier, A. Pignolet, S. G. Cloutier and R. Nechache, Nano Energy, 2018, 51, 324-332.

3 S. D. Stranks, G. E. Eperon, G. Grancini, C. Menelaou, M. J. P. Alcocer, T. Leijtens, L. M. Herz, A. Petrozza and H. J. Snaith, Science, 2013, 342, 341-344.

4 H. S. Jung and N.-G. Park, Small, 2015, 11, 10-25.

5 J. C. Yu, D. Bin Kim, E. D. Jung, B. R. Lee and M. H. Song, Nanoscale, 2016, 8, 7036-7042.

6 B. R. Sutherland and E. H. Sargent, Nat. Photonics, 2016, 10, 295-302.

7 K. Young-Hoon, C. Himchan, H. J. Hyuck, K. Tae-Sik, M. NoSoung, L. Chang-Lyoul, I. S. Hyuk and L. Tae-Woo, Adv. Mater., 2014, 27, 1248-1254.

8 X. Li, D. Bi, C. Yi, J.-D. Décoppet, J. Luo, S. M. Zakeeruddin, A. Hagfeldt and M. Grätzel, Science, 2016, 353, 58-62.

9 J.-H. Im, I.-H. Jang, N. Pellet, M. Grätzel and N.-G. Park, Nat. Nanotechnol., 2014, 9, 927-932.

10 L. Kyung-Geun, K. Hak-Beom, J. Jaeki, K. Hobeom, K. J. Young and L. Tae-Woo, Adv. Mater., 2014, 26, 6461-6466.

11 L. Shen, Y. Lin, C. Bao, Y. Bai, Y. Deng, M. Wang, T. Li, Y. Lu, A. Gruverman, W. Li and J. Huang, Mater. Horiz., 2017, 4, 242-248.

12 G. E. Eperon, S. D. Stranks, C. Menelaou, M. B. Johnston, L. M. Herz and H. J. Snaith, Energy Environ. Sci., 2014, 7, 982-988.

13 I. M. Asuo, P. Fourmont, I. Ka, D. Gedamu, S. Bouzidi, A. Pignolet, R. Nechache and S. G. Cloutier, Small, 2019, 15, 1804150.

14 T. A. Berhe, W.-N. Su, C.-H. Chen, C.-J. Pan, J.-H. Cheng, H.-M. Chen, M.-C. Tsai, L.-Y. Chen, A. A. Dubale and B.-J. Hwang, Energy Environ. Sci., 2016, 9, 323-356.

15 F. El-Mellouhi, E. T. Bentria, S. N. Rashkeev, S. Kais and F. H. Alharbi, Sci. Rep., 2016, 6, 30305.

16 Y.-Y. Zhang, S. Chen, P. Xu, H. Xiang, X.-G. Gong, A. Walsh and S.-H. Wei, Chin. Phys. Lett., 2018, 35, 036104.

17 N. Arora, M. I. Dar, M. Abdi-Jalebi, F. Giordano, N. Pellet, G. Jacopin, R. H. Friend, S. M. Zakeeruddin and M. Grätzel, Nano Lett, 2016, 16(11), 7155-7162.

18 J. Troughton, K. Hooper and T. M. Watson, Nano Energy, 2017, 39, 60-68.

19 S. Trilok, Ö. Senol, S. Alexander, F. Robert, M. Sanjay and M. Tsutomu, Adv. Funct. Mater., 2018, 28, 1706287.

20 Q. Tai, P. You, H. Sang, Z. Liu, C. Hu, H. L. W. Chan and F. Yan, Nat. Commun., 2016, 7, 11105.

21 J. Burschka, N. Pellet, S.-J. Moon, R. Humphry-Baker, P. Gao, M. K. Nazeeruddin and M. Grätzel, Nature, 2013, 499, 316-319.
22 W. Nie, H. Tsai, R. Asadpour, J.-C. Blancon, A. J. Neukirch, G. Gupta, J. J. Crochet, M. Chhowalla, S. Tretiak, M. A. Alam, H.-L. Wang and A. D. Mohite, Science, 2015, 347, 522-525.

23 T. Niu, J. Lu, R. Munir, J. Li, D. Barrit, X. Zhang, H. Hu, Z. Yang, A. Amassian, K. Zhao and S. Liu, Adv. Mater., 2018, 30, 1706576, DOI: 10.1002/adma.201706576.

24 B. Wang, K. Y. Wong, S. Yang and T. Chen, J. Mater. Chem. A, 2016, 4, 3806-3812.

25 D. Liu and T. L. Kelly, Nat. Photonics, 2014, 8, 133-138.

26 Y. Yu, C. Wang, C. R. Grice, N. Shrestha, D. Zhao, W. Liao, L. Guan, R. A. Awni, W. Meng, A. J. Cimaroli, K. Zhu, R. J. Ellingson and Y. Yan, ACS Energy Lett., 2017, 2, 1177-1182.

27 M. Saliba, T. Matsui, J.-Y. Seo, K. Domanski, J.-P. CorreaBaena, M. K. Nazeeruddin, S. M. Zakeeruddin, W. Tress, A. Abate, A. Hagfeldt and M. Grätzel, Energy Environ. Sci., 2016, 9, 1989-1997.

28 N. Arora, M. I. Dar, A. Hinderhofer, N. Pellet, F. Schreiber, S. M. Zakeeruddin and M. Grätzel, Science, 2017, 358, 768-771.

29 J. M. Kadro, N. Pellet, F. Giordano, A. Ulianov, O. Mü, J. Maier, M. Grä and A. Hagfeldt, Energy Environ. Sci., 2016, 10, 3172-3179.

30 D. Gedamu, I. M. Asuo, D. Benetti, M. Basti, I. Ka, S. G. Cloutier, F. Rosei and R. Nechache, Sci. Rep., 2018, 8, 12885.

31 Q. Jiang, D. Rebollar, J. Gong, E. L. Piacentino, C. Zheng and T. Xu, Angew. Chem., Int. Ed., 2015, 54, 7617-7620.

32 A. M. Ganose, C. N. Savory and D. O. Scanlon, J. Phys. Chem. Lett., 2015, 6, 4594-4598.

33 W. Ke, C. Xiao, C. Wang, B. Saparov, H.-S. S. Duan, D. Zhao, Z. Xiao, P. Schulz, S. P. Harvey, W. Liao, W. Meng, Y. Yu, A. J. Cimaroli, C.-S. S. Jiang, K. Zhu, M. Al-Jassim, G. Fang, D. B. Mitzi and Y. Yan, Adv. Mater., 2016, 28, 5214-5221, DOI: 10.1002/adma.201600594.

34 A. Halder, R. Chulliyil, A. S. Subbiah, T. Khan, S. Chattoraj, A. Chowdhury and S. K. Sarkar, J. Phys. Chem. Lett., 2015, 6, 3483-3489.

35 X. Zhang, H. Liu, W. Wang, J. Zhang, B. Xu, K. L. Karen, Y. Zheng, S. Liu, S. Chen, K. Wang and X. W. Sun, Adv. Mater., 2017, 29, 1606405, DOI: 10.1002/adma.201606405.

36 J. Chen, J. Xu, S. Zhang, S. Zhou, K. Zhou, B. Zhang, X. Xia, Y. Liu, S. Dai and J. Yao, J. Phys. Chem. C, 2017, 7, 44.

37 Y.-H. Chiang, M.-H. Li, H.-M. Cheng, P.-S. Shen and P. Chen, ACS Appl. Mater. Interfaces, 2017, 9, 2403-2409.

38 Y. Chen, B. Li, W. Huang, D. Gao and Z. Liang, Chem. Commun., 2015, 51, 11997-11999.

39 W. Ke, C. Xiao, C. Wang, B. Saparov, H.-S. Duan, D. Zhao, Z. Xiao, P. Schulz, S. P. Harvey, W. Liao, W. Meng, Y. Yu, A. J. Cimaroli, C.-S. Jiang, K. Zhu, M. Al-Jassim, G. Fang, D. B. Mitzi and Y. Yan, Adv. Mater., 2016, 28, 5214-5221.

40 M. K. Kim, T. Jeon, H. Il Park, J. M. Lee, S. A. Nam and S. O. Kim, CrystEngComm, 2016, 18, 6090-6095.

41 Y. Zhou, O. S. Game, S. Pang and N. P. Padture, J. Phys. Chem. Lett., 2015, 6, 4827-4839.

42 T. S. Sherkar, C. Momblona, L. Gil-Escrig, J. Ávila, M. Sessolo, H. J. Bolink and L. J. A. Koster, ACS Energy Lett., 2017, 2(5), 1214-1222, DOI: 10.1021/acsenergylett.7b00236. 
43 N. Liu, Q. Du, G. Yin, P. Liu, L. Li, H. Xie, C. Zhu, Y. Li, H. Zhou, W.-B. Zhang and Q. Chen, J. Mater. Chem. A, 2018, 6, 6806-6814.

44 T. J. Jacobsson, J. P. Correa-Baena, E. Halvani Anaraki, B. Philippe, S. D. Stranks, M. E. F. Bouduban, W. Tress, K. Schenk, J. Teuscher, J. E. Moser, H. Rensmo and A. Hagfeldt, J. Am. Chem. Soc., 2016, 138, 10331-10343.

45 P. Scherrer, Nachrichten von der Gesellschaft der Wissenschaften zu Göttingen, Math. Klasse, 1918, pp. 98-100.

46 H.-S. Kim and N.-G. Park, J. Phys. Chem. Lett., 2014, 5, 2927-2934.

47 C. Lan, J. Luo, H. Lan, B. Fan, H. Peng, J. Zhao, H. Sun, Z. Zheng, G. Liang and P. Fan, Materials, 2018, 11(3), 355, DOI: $10.3390 / \mathrm{ma11030355.}$

48 F. Giordano, A. Abate, J. P. Correa Baena, M. Saliba, T. Matsui, S. H. Im, S. M. Zakeeruddin, M. K. Nazeeruddin, A. Hagfeldt and M. Graetzel, Nat. Commun., 2016, 7, 10379.

49 E. Zimmermann, P. Ehrenreich, T. Pfadler, J. A. Dorman, J. Weickert and L. Schmidt-Mende, Nat. Photonics, 2014, 8, 669-672.

50 A. Nakane, H. Tampo, M. Tamakoshi, S. Fujimoto, K. M. Kim, S. Kim, H. Shibata, S. Niki and H. Fujiwara, J. Appl. Phys., 2016, 120, 064505.

51 G.-J. A. H. Wetzelaer, M. Scheepers, A. M. Sempere, C. Momblona, J. Ávila and H. J. Bolink, Adv. Mater., 2015, 27, 1837-1841.

52 D. Bi, W. Tress, M. I. Dar, P. Gao, J. Luo, C. Renevier, K. Schenk, A. Abate, F. Giordano, J.-P. Correa Baena, J.-D. Decoppet, S. M. Zakeeruddin, M. K. Nazeeruddin, M. Grätzel and A. Hagfeldt, Sci. Adv., 2016, 2, e1501170.

53 Z. Chu, M. Yang, P. Schulz, D. Wu, X. Ma, E. Seifert, L. Sun, X. Li, K. Zhu and K. Lai, Nat. Commun., 2017, 8, 2230.

54 Y. Rong, Y. Hu, S. Ravishankar, H. Liu, X. Hou, Y. Sheng, A. Mei, Q. Wang, D. Li, M. Xu, J. Bisquert and H. Han, Energy Environ. Sci., 2017, 10, 2383-2391.
55 L. K. Ono, Y. Qi and S. Frank Liu, Joule, 2018, 2, 1961-1990. 56 Z. Wang, D. P. McMeekin, N. Sakai, S. van Reenen, K. Wojciechowski, J. B. Patel, M. B. Johnston and H. J. Snaith, Adv. Mater., 2017, 29, 1604186.

57 X. Du, T. Heumueller, W. Gruber, A. Classen, T. Unruh, N. Li and C. J. Brabec, Joule, 2018, 1-12.

58 N. Y. Doumon, G. Wang, R. C. Chiechi and L. J. A. Koster, J. Mater. Chem. C, 2017, 5, 6611-6619.

59 J. A. Röhr, X. Shi, S. A. Haque, T. Kirchartz and J. Nelson, Phys. Rev. Appl., 2018, 9, 044017.

60 R. H. Bube, J. Appl. Phys., 1962, 33, 1733-1737.

61 K. Poorkazem and T. L. Kelly, Sustainable Energy Fuels, 2018, 2, 1332-1341.

62 P. N. Murgatroyd, J. Phys. D: Appl. Phys., 1970, 3, 308.

63 C. Chiang and C. Wu, Nat. Photonics, 2016, 10, 196-200.

64 W. Zhou, P. Zhou, X. Lei, Z. Fang, M. Zhang, Q. Liu, T. Chen, H. Zeng, L. Ding, J. Zhu, S. Dai and S. Yang, ACS Appl. Mater. Interfaces, 2018, 10(2), 1897-1908, DOI: 10.1021/acsami. $7 \mathrm{~b} 15008$.

65 N. Y. Doumon, M. V. Dryzhov, F. V. Houard, V. M. Le Corre, A. Rahimi Chatri, P. Christodoulis and L. J. A. Koster, ACS Appl. Mater. Interfaces, 2019, 11, 8310-8318.

66 N. Y. Doumon, F. V. Houard, J. Dong, H. Yao, G. Portale, J. Hou and L. J. A. Koster, Org. Electron., 2019, 69, 255-262.

67 N. Y. Doumon, F. V. Houard, J. Dong, P. Christodoulis, M. V. Dryzhov, G. Portale and L. J. A. Koster, J. Mater. Chem. C, 2019, 7, 5104-5111.

68 D. Bartesaghi, I. D. C. Pérez, J. Kniepert, S. Roland, M. Turbiez, D. Neher and L. J. A. Koster, Nat. Commun., 2015, 6, 7083.

69 Perovskite Inks|Pi-SOL Technologies Inc.|Canada, https:// www.pisoltechnologies.com/, accessed 25 June 2019.

70 I. Ka, I. M. Asuo, S. Basu, P. Fourmont, D. M. Gedamu, A. Pignolet, S. G. Cloutier and R. Nechache, Small, 2018, 14, 1802319. 